\title{
O mito de Brasília e a literatura ${ }^{1}$
}

\author{
JOÃO ALMINO
}

$\mathrm{F}$

ALO COMO QUEM situou três romances em Brasília, trilogia que corre sério

risco de se transformar num quarteto ${ }^{2}$. Não me caberia fazer uma crítica de meu trabalho. Mas gostaria de tomá-lo como referência para desenvolver uma reflexão sobre Brasília como projeto e realização de uma nação e a relação que isso possa ter com a literatura. Se há uma diferença entre o narrador e o autor, não é menor a distância entre ambos e o ensaísta que se refere à sua obra, uma distância tão grande quanto a que separa um artigo sobre música da execução de uma peça, ou um comentário de cinema da projeção de um filme. Quem fala aqui, portanto, não é o autor dos romances nem seu narrador, mas uma terceira persona, que veste provisoriamente o chapéu do ensaísta.

Não tendo nascido nem crescido em Brasília, às vezes me perguntam por que escolhi aquela cidade como cenário ou personagem de meus romances - já se vão agora mais de trinta anos das primeiras anotações e quase vinte da publicação do primeiro livro da trilogia, Idéias para onde passar o fim do mundo. Embora, repito, não pretenda girar em torno de minha literatura, este ensaio é uma tentativa de resposta àquela pergunta.

Permitam-se, a título de introdução, uma pequena nota pessoal. Algumas de minhas histórias poderiam certamente situar-se em lugares distintos de Brasília ou talvez em países distintos do Brasil. Uma cidade não é suficiente para definir um romance. Pode haver mais pontos de contato entre duas histórias que se passam respectivamente no Rio e em Nova York do que entre duas outras na mesma cidade. No entanto, devo admitir: escolhi Brasília, não outras cidades onde também vivi.

Quando comecei a escrever ficção, pensei que, se pudesse transpor algumas histórias do Nordeste do Brasil - onde nasci - para Brasília, a atmosfera dessa cidade improvável lhes agregaria alguns elementos de estranheza, ajudando-me a eliminar estereótipos e a desfamiliarizar a realidade. Em 1985, o Brasil tinha regressado a um governo civil, já não havia presos políticos, e a democracia parecia uma opção viável para o país. A literatura tinha que mudar diante do novo clima político.

Ao lidar com o dia-a-dia, com a cidade real, uma literatura que retratasse Brasília podia, a meu ver, se beneficiar não apenas de sua história e de sua geografia, mas também de sua dimensão mítica, o mito entendido como uma narrativa de significação simbólica.

Algumas cidades mostram de si uma imagem recorrente, como um palimpsesto ou uma fotografia antiga que permanecesse impressa, ainda que amarelecendo com o tempo, e conservasse seus traços por trás de outras, mais vivas e atuais. 
No caso de Brasília é imagem forjada pelo mito e também pela história de uma idéia, que se conclui com a execução do seu projeto modernista. Para dizer de outra forma, aquela cidade sem história é rica em carga simbólica. E o que Brasília simboliza? A democracia. A racionalidade. A nação. A integração e o desenvolvimento. A aspiração de igualdade. O moderno. O futuro. E também, claro, o poder, a alienação, o encastelamento, a corrupção, o autoritarismo, o misticismo e a irracionalidade.

Poucas cidades do mundo têm uma carga simbólica tão forte. Não importa que a realidade negue ou venha a negar o que a idéia de Brasília representa ou representou ao longo dos tempos. Mitos não se destroem facilmente; sobrevivem à própria realidade material.

Lembro-me do dia da inauguração de Brasília, eu ainda criança, toda a minha família ao pé do rádio, lá em Mossoró, no Rio Grande do Norte, como milhões de outras famílias espalhadas por todo o país. Não foi apenas no Brasil que a construção de Brasília atraiu as atenções, de um lado sendo vista com ceticismo, de outro produzindo espanto e admiração. Fotos da cidade em construção vinham estampadas em jornais e revistas em várias partes do mundo. Muitos foram seus visitantes ilustres: chefes de Estado, como Dwight Eisenhower, dos Estados Unidos, e Fidel Castro, de Cuba, atores, como o inglês David Niven, e escritores, como Jean-Paul Sartre e Aldous Huxley. Entre outros, Clarice Lispector, André Malraux, John dos Passos e Simone de Beauvoir registraram suas impressões sobre a nova capital. Charles Aznavour lhe dedicou uma canção e Tom Jobim e Vinicius de Moraes, uma sinfonia. Sua inauguração atraiu o maior número de visitantes brasileiros e estrangeiros em toda a história brasileira até aquela data, 21 de abril de 1960.

A maioria das cidades resulta do acaso, do encontro fortuito e da necessidade. Brasília é obra do espírito, da vontade e do plano. Se a experiência concreta daqueles que lá vivem ainda tem uma história curta, a história de Brasília como projeto, símbolo e mito se confunde com a do Brasil independente. É a história de uma utopia construída ao longo de um século e meio.

A interiorização da capital, não ainda necessariamente para o Planalto Central, foi defendida inicialmente como fruto dos ideais nacionalistas, pelos inconfidentes mineiros e pelos revolucionários de 1817, em Pernambuco, e também, a partir de 1808, por Hipólito José da Costa, que, de seu exílio londrino, localizava a nova capital no "interior central", nas "cabeceiras dos grandes rios".

Ainda antes da independência, em 1821, José Bonifácio de Andrade e Silva sugeriu, nas "instruções dos Deputados Paulistas à Corte", que se levantasse "uma cidade central no interior do Brasil para assento da Corte ou da Regência", acrescentando que poderia ser "na latitude pouco mais ou menos de 15 graus", o que veio a coincidir com a futura localização de Brasília. No mesmo documento, Bonifácio propunha que a nova cidade tivesse a "denominação de Petrópole, Brasília ou outra qualquer”. 
A interiorização era vista não apenas como instrumento de segurança. Naquelas instruções já se encontrava o embrião do futuro projeto desenvolvimentista de Kubitschek ou de integração nacional dos militares. "Daquela Corte, central, proposta" - afirmavam as instruções - "dever-se-ão logo abrir estradas para as diversas províncias e portos de mar, para que se comuniquem e circulem com prontidão as ordens do governo e se favoreça por elas o comércio interno do vasto Império do Brasil". Essas idéias serão retomadas na memória "sobre a necessidade e os meios de edificar no interior do Brasil uma nova capital", apresentada pelo mesmo Bonifácio à Assembléia Constituinte brasileira, em 1823. Serão também mais tarde expandidas pelo historiador e diplomata Francisco Varnhagen, o visconde de Porto Seguro, entre outros escritos, em seu Memorial orgânico, de 1849.

Ali Varnhagen, responsável pela indicação de uma localização ainda mais precisa para a nova capital, apontava, além das razões de segurança, fatores geradores de riqueza, de unidade nacional, integração e civilização. Para ele, o emprego de "capitais produtivos" no interior aumentaria "sua cultura e riqueza, e depois sua população". Seria necessário levar "como tônicos" aos sertões "grandes focos de civilização, e não o pode haver melhor do que o de assentar aí a capital, que em todos os reinos é centro do luxo...". Seria uma maneira de manter vivo o próprio Estado. Diz ele que "os governos cuja sede está no interior do país tratam mais que os outros em cuidar de facilitar as comunicações, que são as veias e as artérias do Estado, que sem elas definha e morre". Há também o argumento da irradiação equânime da administração - e, portanto, do bom governo - a partir do centro: "ao mesmo tempo, uma capital central pode distribuir com mais igualdade, em diferentes raios, sua solicitude". O comércio interno e a geração de riqueza daí decorrentes seriam criados pelo consumo dessa capital interiorana. Ali se cultivariam artigos de comércio "que não cultiva a beiramar" e pouco a pouco se criaria uma auto-suficiência. A população "pastoril passaria a ser agricultora, e até com o tempo, a ensaiar-se a outros ramos d'industria”.

Em outros escritos do século XIX, a nova capital simbolizava também a autoridade que se espraiaria por todo o território nacional. Em carta dirigida ao ministro da Agricultura, Tomás Coelho, por exemplo, em 1877, assinalava que sua localização, no centro do país, parecia estar indicada "pela natureza na própria região elevada do seu território, donde baixariam as ordens, como baixam as águas que vão pelo Tocantins ao Norte, pelo Prata ao Sul e pelo São Francisco a Leste".

Não falta à história do projeto de Brasília também a dimensão mística. D. Bosco, o santo fundador da ordem dos salesianos, teria tido em $1883 \mathrm{um}$ sonho profético sobre a "Terra Prometida", num "leito muito largo e muito extenso, partindo de um ponto onde se forma um lago", "entre os paralelos 12 e 20 " e onde seria fundada "uma nova civilização".

É possível citar várias outras provas de que a idéia de mudança da capital esteve presente no imaginário das lideranças políticas e de muitos outros brasi- 
leiros especialmente a partir da segunda metade do século XIX, e adquiriu sua legitimidade como elemento fundamental da construção da nação, bem como da promoção de sua riqueza. O "Projeto de Lei de Mudança da Capital", em parte inspirado nos escritos de Varnhagen, do senador Holanda Cavalcanti, de Pernambuco, de 1852, a situava nas "latitudes de 10 a 15 graus-Sul", no Planalto Central. O artigo $3^{\circ}$ da Constituição de 1891 destinava à União, no Planalto Central, uma zona de 14.400 quilômetros a ser "demarcada para nela estabelecer-se a futura Capital Federal". E em 1892, o presidente Floriano Peixoto designou uma Comissão, sob a presidência do diretor do Observatório Nacional, Luiz Cruls, para "proceder à demarcação da área e fazer sobre a zona os indispensáveis estudos", o que foi realizado ao longo de quatro anos.

O fundador e primeiro presidente desta Academia, Machado de Assis, não esteve alheio à importância do assunto. Dizia, em sua crônica semanal de 22 de janeiro de 1893, que “a questão Capital está na ordem do dia”, e dava notícia dos trabalhos da Comissão Cruls. Afirmava:

Quanto à capital da república, é matéria constitucional, e a comissão encarregada de escolher e delimitar a área já concluiu os seus trabalhos, ou está prestes a fazê-lo, segundo li esta mesma semana. Telegrama de Uberaba diz que ali chegou o chefe, Luís Cruls. Não há dúvida que uma capital é obra dos tempos, filha da história. A história e os tempos se encarregarão de consagrar as novas. A cidade que já estiver feita, como no Estado do Rio, é de esperar que se desenvolva com a capitalização. As novas devemos esperar que serão habitadas logo que sejam habitáveis. O resto virá com os anos.

E acrescentava Machado, numa indicação da expectativa de que a mudança ocorreria ainda num futuro não tão longínquo: "Não sei se viverei até a inauguração. A vida é tão curta, a morte tão incerta que a inauguração pode fazer-se sem mim, e tão certo é o esquecimento, que nem darão pela minha falta".

Mais de três anos depois, o assunto ainda o interessava. Noutra de suas crônicas semanais, essa de 7 de junho de 1896, afirmava, ao se discutir um projeto de lei que visava conservar o Rio de Janeiro como capital, que "a questão da capital ... a nossa questão capital teve esta semana um impulso". E uma vez mais registrava os trabalhos da Comissão Cruls: "a Constituição determina que no planalto de Goiás, seja demarcado o território da nova capital, e já lá trabalha uma comissão de engenheiros".

Pedia ao leitor que não imaginasse que falava "pela tristeza de ver decapitada a minha boa cidade carioca. Tristeza tenho em verdade; mas tristezas não valem razões de Estado; e, se o bem comum o exige, devem converter-se em alegrias".

A idéia da mudança da capital continuou viva, como sonho de visionários e intérpretes da vontade nacional e do destino de um povo. São indicações disso as grandes discussões públicas sobre a matéria, ocorridas em 1905, de que participaram jornalistas e escritores renomados, como Olavo Bilac e Euclides da Cunha; o lançamento da pedra fundamental no Planalto Central, no centenário 
da Independência, sob o governo de Epitácio Pessoa; a inclusão de dispositivos sobre a transferência da capital para "o ponto central do Brasil” na Constituição de 1934; ou para o Planalto Central, conforme estabelecia o artigo $4^{\circ}$ das Disposições Transitórias da Constituição de 1946; os estudos técnicos para sua precisa localização durante os governos Dutra, Vargas e Café Filho, até aquela idéia constituir-se na "Meta-Síntese", de grandeza épica, do Programa de Metas do governo Kubitschek e transformar-se, no dizer do mais recente eleito para esta Academia, o ex-chanceler Celso Lafer (2002, p.307), no "símbolo da dimensão de Juscelino como o estadista que fez surgir a racionalidade superior do novo a partir do existente" (texto de apresentação do livro Brasil, Brasilita e os brasileiros, da Fundação Israel Pinheiro). O país parecia finalmente estar chegando a seu futuro.

Talvez a defesa mais eloqüente do valor simbólico da nova capital no momento mesmo de sua fundação tenha sido feita por André Malraux, quando de sua visita oficial ao Brasil como ministro da Cultura da França. Como afirmou Lafer (2002, p.275), “a voz do autor d'A condição humana foi a primeira a proclamar o alcance simbólico da construção de Brasília e a realçar a dimensão espiritual de seus espaços e edifícios". Para Malraux, em seu discurso de 25 de agosto de 1959, pronunciado em Brasília, sendo "a ressurreição do lirismo arquitetural nascido com o mundo helênico", aquela cidade era "um pouco a acrópole em seu rochedo", a "capital da esperança”, "a primeira das capitais da nova civilização", "a cidade mais audaciosa que o Ocidente já concebeu” e que "lembra ao mundo que os monumentos estão a serviço do espírito". Naquele mesmo discurso, o escritor francês que veio a ser eleito em 1967 o sócio correspondente de número 13 desta Academia, acreditava, como Lúcio Costa, que "a cidade não [seria] apenas a sede do novo governo e da administração, mas também um dos maiores centros culturais do país". "As grandes nações sempre encontram seu símbolo, e sem dúvida Brasília é um símbolo de tal sorte" (Malraux, 1988, p.33-41), acrescentava.

Diz James Holston (1993, p.23) em seu livro A cidade modernista. Uma crítica de Brasília e sua utopia, que os visionários que sonharam com a mudança da capital "deixaram a Brasília o legado de uma mitologia do Novo Mundo em que a construção de uma capital no Planalto Central seria o meio de desencadear o florescimento de uma grande civilização num paraíso de abundância”. O projeto de Brasília deveria "exprimir a grandeza da vontade nacional", conforme assinalava o relatório do júri do concurso. Brasília "devia instituir um novo sistema de vida" e constituir uma mensagem capaz, entre outras coisas, "de comunicar ideais de vida democrática" e "de auto-identificação triunfal de um país jovem”, como observou Umberto Eco (2001, p.244), em seu livro A estrutura ausente, originalmente publicado em 1968.

A cidade nasceu sob o manto do sagrado, representado pelo signo da cruz. Ainda durante o governo Café Filho, é fincada a cruz de madeira no ponto mais alto da área demarcada, hoje Praça do Cruzeiro, marco da fundação da cidade, 
local onde mais tarde, em maio de 1957, foi rezada a primeira missa. O poeta e acadêmico Guilherme de Almeida saudou a inauguração com um poema que dizia: "agora e aqui todos se cruzam pelo sinal da Santa Cruz". A cruz está no próprio projeto urbanístico e nas palavras com que Lúcio Costa o descreveu: "nasceu do gesto primário de quem assinala um lugar ou dele toma posse: dois eixos cruzando-se em ângulo reto, ou seja, o próprio sinal-da-cruz".

A utopia de Brasília estava expressa naquela cruz. O eixo monumental abrigava o sonho de realização da nação. A monumentalidade desejada correspondia à ambição do projeto e era proporcional à grandeza de seu ideal. Uma cidade de iguais surgiria a longo do eixo residencial. Brasília devia fundar um novo país, moderno como a arquitetura de sua capital; ser a base de uma nova e mais justa sociedade.

O Plano Piloto era um espaço de possibilidades. Estava associado ao novo: um novo homem, uma nova política. Seu tema mais visível era a busca do moderno, a discussão sobre o renascimento, sobre o novo começo. Por sua vez, sua cartografia virá também a empregar os limites e a transgressão como símbolos; a enfocar imagens da revolução e do fim do mundo.

Com a cidade inaugurada, a utopia de Brasília começava a se confrontar com a Brasília real. Diz uma das principais estudiosas de Brasília, a socióloga Bárbara Freitag (2003, p.75), que aquela cidade "recebeu em seu espaço urbano todos os problemas da sociedade brasileira sem correções prévias. Não é de admirar", ela acrescenta, "que neste verdadeiro 'laboratório social' vejamos a olho nu e convivamos de forma mais direta com os problemas globais da sociedade brasileira como um todo".

O projeto de desenvolvimento e a modernidade passavam pela educação. Por intermédio da Universidade de Brasília, Darcy Ribeiro e Anísio Teixeira pretendiam que a nova capital se transformasse no centro inovador do pensamento crítico brasileiro. Na música Cláudio Santoro, na crítica Paulo Emílio Sales Gomes, no cinema o hoje imortal Nelson Pereira dos Santos, na arquitetura aquele que projetou os principais prédios e monumentos da cidade, Oscar Niemeyer, foram alguns dos nomes que passaram pela universidade. Mas veio a ditadura militar, e a universidade sofreu sua primeira invasão por tropas policiais já em 1965. Quinze professores foram presos e 210 se demitiram. Entre outros, Nelson Pereira dos Santos e Niemeyer deixaram a universidade naquela ocasião. Outra invasão ocorreu em 1968, quando quinhentos alunos foram detidos por militares e o corpo docente foi demitido em massa.

Com o tempo, descobriu-se o que era óbvio: não é o plano urbanístico que molda a sociedade, mas essa que vai dando novos significados àquele. Mesmo quando preservada, a arquitetura absorve o espírito do tempo, moldando-se às novas realidades. Brasília recebeu o impacto das transformações políticas brasileiras, bem como da revolução dos costumes dos anos 1960 e 1970. Com a expansão das cidades satélites, a urbe que havia nascido com o sonho da igualdade 
tornava a desigualdade mais patente do que em qualquer outro centro urbano brasileiro. Com os militares, a cidade que havia sido inaugurada sob um governo democrático passava a espelhar a imagem do autoritarismo. Simbolicamente, porém, como centro do poder, ela estava associada à luta contra a ditadura e à ilusão revolucionária. Teve também a sua geração do desbunde, que projetou seu roque.

Brasília obedece a um plano racional e quase matemático, onde a classificação foi levada ao extremo. É sem dúvida a cidade moderna por excelência no sentido de que é a realização do projeto moderno dos anos 1950 e, mais ainda, a execução mais acabada das propostas consubstanciadas nos manifestos dos Congressos Internacionais de Arquitetura Moderna (Ciam), realizados de 1928 até meados da década de 1960, e que tiveram em Le Corbusier um de seus expoentes. Por isso, convida a pensar sobre a idéia do moderno que a fundou, uma idéia que envelheceu com ela, mas que ainda habita a imaginação dos brasileiros. Brasília, "mistério classificado em arquivos de aço", "é um futuro que aconteceu no passado", dizia Clarice Lispector.

Esse projeto moderno e racional é confrontado pela criação espontânea. Há um contraste entre o caos e a ordem, entre as linhas retas do Plano Piloto, onde os carros circulam, e as veredas sinuosas que os pedestres criam livremente sobre a grama, como formas de resistência à planificação. Muitas das supostas construções modernas envelheceram prematuramente e estão cobertas de graffiti.

O projeto moderno e racional se mescla também com a expressão pré-moderna e irracional que prolifera dentro e em torno de si. A cidade se vê rodeada pela irracionalidade de várias seitas místicas. Algumas delas vislumbram no Planalto Central uma grandeza paralela à do papel civilizador da interiorização: em contraponto ao triângulo eqüilátero que, no plano de Lúcio Costa, define a área da cidade, existiria um triângulo muito maior, localizado no Planalto Central, que sobreviveria à grande catástrofe que estaria por vir e seria o berço de uma nova era e uma nova humanidade. Acrescente-se a esse contraste gritante com a modernidade outro, silencioso e corriqueiro: por seu caráter geograficamente goiano, a cidade foi também absorvendo a atmosfera do Brasil profundo e tradicional. Aliás, lingüisticamente é sobretudo goiana.

Estão, assim, exacerbadas em Brasília tanto a tensão entre a racionalidade geométrica e a vivência criativa do cotidiano, existente em toda cidade - como já nos mostrou Ítalo Calvino (1990, p.85) em suas Seis propostas para o próximo milênio -, quanto a tensão entre o moderno e o arcaico que parece estar no coração do mundo contemporâneo.

Ao longo de sua curta história, alguns traços permanecem. Um aspecto do perfil psicológico do Plano Piloto é sua artificialidade. "Brasília é artificial. Tão artificial quanto devia ter sido o mundo quando foi criado", escreveu Clarice Lispector. Diz-se com freqüência que aquela cidade foi feita para a passagem rápida dos automóveis. Ali há poucos lugares públicos de encontro, não há ruas, 
esquinas ou calçadas do tipo usual, e há relativamente poucos pedestres. Claro, a artificialidade é própria dos centros urbanos. Mas se pode considerar "natural" um desenvolvimento urbano que seja a conseqüência espontânea da história de um lugar e das relações que as pessoas estabelecem entre si. Não é o caso de Brasília. Sua configuração assinala sua natureza artificial. Totalmente planejada e tendo sido concebida sobretudo para sua função política, a cidade original não foi de forma alguma resultado de uma evolução espontânea e orgânica. Os pequenos rios da região do Planalto Central não contribuíram para a formação da cidade, nem ela cresceu sobre suas margens. Suas águas escassas foram utilizadas para conformar o Lago Paranoá. O Plano Piloto abraça, com suas asas, o lago artificial que é fundamental tanto para aliviar a secura do ar quanto para as atividades lúdicas sobre o espelho de água ou no que sobrou das margens privatizadas. Já a pequena lagoa que antecedeu Brasília, a Lagoa Jaburu, atualmente situada no terreno do palácio do vice-presidente, vem secando desde o nascimento da cidade.

Na enorme Cidade Parque, não se caminha com sentido utilitário, para ir às compras, ao trabalho. Passeia-se, exercita-se. A artificialidade que invade a paisagem - a natureza reinventada pelos homens e que ainda guarda exemplos do gênio de Burle Marx - está também presente na flora do Plano Piloto.

Falta de espaço é comum nas cidades modernas, onde os edifícios altos bloqueiam o horizonte. Ali é o contrário. Ante os amplos horizontes e a longa distância entre os prédios, os humanos se sentem pequenos e solitários. Tanto a grandeza quanto a artificialidade da paisagem urbana freqüentemente inspiram uma sensação de estranheza positiva ou negativa entre os visitantes e até mesmo entre os habitantes da cidade. Embora sem os resultados sociais esperados pelos modernistas, ocorreu uma desfamiliarização. Brasília, em alguma medida, ainda não é uma cidade como as outras e isso em parte se deve a seu Plano Piloto.

Creio que são traços positivos para a literatura não apenas essas, mas também outras características, às vezes apontadas como defeitos, mas que poderiam inspirar um ideário estético-literário.

Essa cidade sem raízes, povoada de migrantes, onde a identidade é aberta e múltipla, recusa a noção da origem única. Aqui as origens podem aparentar o que são de fato: mitos, ou referências cambiantes. A cidade serve de vacina contra o pitoresco. Aqui a cultura não é corpo normativo, uma moral ou uma coleção de pensamentos ou comportamentos congelados. Brasília requer todos os legados que se possa recolher de múltiplas memórias.

Considerada pela Unesco patrimônio da humanidade, fruto de um projeto modernista que transcendeu as fronteiras brasileiras e parte de uma herança mundial, seu caráter é universal.

Sem passado e com futuro ainda em aberto, associada com o surgimento de uma nova sociedade, sugere pensar sobre como habitar o relativo vazio de história e de espaço. Legitima a liberdade de imaginação. 
Uma cidade é como um caleidoscópio de combinações infinitas. É feita de prismas, perspectivas. Está aberta ao olhar subjetivo do seu flâneur, do seu habitante, turista, daquele que a observa de longe, como idéia. Poderá haver, portanto, várias literaturas de Brasília.

Elas se fazem com histórias de verdade, com a verossimilhança, com emoções, com evocação de dramas verdadeiros. Mas, em qualquer delas, a camada mítica - aquela foto amarelada, imagem recorrente, de que eu falava no começo - as enriquece, como se fosse uma segunda linguagem.

Tento não idealizar essa cidade. Não a vejo como modelo. Pratico o pessimismo como método criativo. Isso não significa que somente tenho expectativas negativas, que desconfio de toda noção de progresso ou que vejo a decadência como fatalidade. O papel dos escritores não é o de fazer profecias. É o de tentar iluminar o que parece obscuro e de tornar opaco o que parecia claro. Ao fazê-lo, chamam a atenção para o lado sombrio da existência e também para as utopias negativas, às vezes com a esperança de evitar que se tornem reais. Brasília é um retrato do Brasil, com seus vícios e a miséria corroendo o forte desejo de modernização.

Conhecê-la não é conhecer a Esplanada dos Ministérios, nem a Praça dos Três Poderes, nem as superquadras, tampouco o Lago Sul ou as cidades satélites. É sentir por dentro o peso de seu drama, de suas intrigas, de seus contrastes, sua desordem disfarçada de linhas retas, sua modernidade carcomida e suja, sua poeira e sua luz, as lágrimas derramadas e os risos ouvidos nos corredores do Congresso, o clamor de suas multidões na Esplanada, sua beleza e seu sonho de igualdade, aquilo tudo de que é possível extrair um resto de esperança, a constante lembrança de seus mitos e utopia e a insatisfação com a realidade que alimenta a boa literatura.

No fundo, o Plano Piloto continua sendo um espaço de possibilidades. Sua utopia pode ser recriada, não como uma aspiração ao ideal, mas como uma ocupação presente dos espaços existentes, como uma redefinição das relações possíveis, como a criação de novas formas de organizar o caos - em resumo, como uma nova percepção do que é. Essa nova percepção poderia mostrar-se como guia para o processo necessário por meio do qual Brasília se tornaria gradualmente menos um plano incompleto ou fracassado e mais um lugar moldado por uma história viva e por problemas urgentes, ou seja: uma cidade como a maioria das demais, mas que guardasse ainda, por não ser possível apagá-la, sua dimensão mitológica. Como dizia Machado de Assis, "a história e os tempos se encarregarão de consagrar as novas" cidades - e poderíamos acrescentar: para aquelas que nascem cheias de promessa, de destruir suas ilusões.

\section{Notas}

l Conferência pronunciada na Academia Brasileira de Letras, em 24 de agosto de 2006.

2 O quarto romance, intitulado O livro das emoções, será publicado em 2008 pela Record. 
Referências bibliográficas

ALMINO, J. Idéias para onde passar o fim do mundo. São Paulo: Brasiliense, 1987. . Samba-enredo. São Paulo: Marco Zero, 1994. . As cinco estações do amor. Rio de Janeiro: Record, 2001.

CALVINO, I. Seis propostas para o próximo milênio. São Paulo: Cia. das Letras, 1990.

ECO, U. A estrutura ausente. São Paulo: Perspectiva, 2001.

FREITAG, B. Brasília refletida. In: Abstrata Brasília concreta. Brasília: Medialecom, 2003.

FUNDAÇÃO ISRAEL PINHEIRO. Brasil, Brasilia e os brasileiros. Brasília: Fundação Israel Pinheiro, 2002.

HOLSTON, J. A cidade modernista. Uma crítica de Brasília e sua utopia. São Paulo: Cia. das Letras, 1993.

LAFER, C. Mudam-se os tempos. Brasília: Ipri, 2002.

MALRAUX, A. Palavras no Brasil. Org. e Trad. Edson Rosa da Silva. Rio de Janeiro: Funarte, 1998.

RESUMO - Havendo situado vários de seus romances em Brasília, o autor defende que uma literatura que retrate aquela cidade pode se beneficiar de sua dimensão mítica e de traços que lhe são próprios, aqui discutidos. A imagem de Brasília é forjada pelo mito e pela história de uma idéia, que se conclui com a execução do seu projeto modernista. Poucas cidades do mundo têm uma carga simbólica tão forte. A história de Brasília é a história de uma utopia construída ao longo de um século e meio. Com a cidade inaugurada, essa utopia passou a se confrontar com a Brasília real, estando ali exacerbadas tanto a tensão entre a racionalidade geométrica e a vivência criativa do cotidiano quanto a tensão entre o moderno e o arcaico.

PALAVRAS-CHAVE: Mito e literatura, Brasília - história, Utopia, Projeto modernista.

ABSTRACT - Having set several novels in Brasilia, the author of this essay suggests that a fiction representing that city could benefit from its mythic dimension and from other traits discussed here. Brasilia's image is shaped by myth and by the history of an idea that culminates with its modernistic project. Very few cities in the world have such a strong symbolic power. Brasilia's history is the history of a utopia built throughout a hundred and fifty years. After the city's inauguration, this utopia came face to face with the real Brasilia, thus exacerbating the tensions between geometric rationality and creative life, the modern and the old.

KEYWORDS: Myth and literature, Brasilia - history, Utopia, Modernistic project.

João Almino é escritor e diplomata, autor da Trilogia de Brasilia, composta pelos romances Idéias para onde passar o fim do mundo, Samba-enredo e As cinco estações do amor (prêmio Casa de las Américas 2003). É também autor de sete outros livros, nos campos da história, literatura e filosofia política. @ - joaoalmino@hotmail.com

Recebido em 25.8.2006 e aceito em 5.9.2006. 